NASA/TM-1998-206531

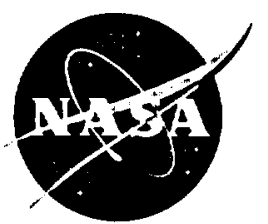

\title{
Verification of Space Station Secondary Power System Stability Using Design of Experiment
}

Kamiar J. Karimi, Andrew J. Booker, and Alvin C. Mong

Boeing Information and Support Services, Seattle, Washington

Bruce Manners

Lewis Research Center, Cleveland, Ohio

Prepared for the

32nd Intersociety Energy Conversion Engineering Conference cosponsored by AIChE, ANS, SAE, AIAA, ASME, and IEEE

Honolulu, Hawaii, July 27-August 1, 1997

National Aeronautics and

Space Administration

Lewis Research Center 
This report contains preliminary findings, subject to revision as analysis proceeds.

Available from

NASA Center for Aerospace Information 800 Elkridge Landing Road

Linthicum Heights, MD 21090-2934

Price Code: A03
National Technical Information Service 5287 Port Royal Road Springfield, VA 22100

Price Code: A03 


\title{
VERIFICATION OF SPACE STATION SECONDARY POWER SYSTEM STABILITY USING DESIGN OF EXPERIMENT
}

\author{
Kamiar J. Karimi \\ Andrew J. Booker \\ Alvin C. Mong \\ Boeing Information and Support Services, MS 7L-25 \\ Seattle, WA 98124 \\ Bruce Manners \\ NASA LeRC \\ 21000 Brookpark Road, Cleveland, OH 44135
}

\begin{abstract}
This paper describes analytical methods used in verification of large DC power systems with applications to the International Space Station (ISS). Large DC power systems contain many switching power converters with negative resistor characteristics. The ISS power system presents numerous challenges with respect to system stability such as complex sources and undefined loads. The Space Station program has developed impedance specifications for sources and loads. The overall approach to system stability consists of specific hardware requirements coupled with extensive system analysis and testing. Testing of large complex distributed power systems is not practical due to size and complexity of the system. Computer modeling has been extensively used to develop hardware specifications as well as to identify system configurations for lab testing. The statistical method of Design of Experiments (DoE) is used as an analysis tool for verification of these large systems. DoE reduces the number of computer runs which are necessary to analyze the performance of a complex power system consisting of hundreds of $\mathrm{DC} / \mathrm{DC}$ converters. DoE also provides valuable information about the effect of changes in system parameters on the performance of the system. DoE provides information about various operating scenarios and identification of the ones with potential for instability. In this paper we will describe how we have used computer modeling to analyze a large DC power system. A brief description of DoE is given. Examples using applications of $D o E$ to analysis and verification of the ISS power system are provided.
\end{abstract}

\section{INTRODUCTION}

The International Space Station Electric Power Systems includes multiple levels of switching DC/DC converters to provide voltage levels required by various electrical loads (core loads and payloads). Primary DC power is generated by solar arrays and batteries. This DC power is regulated by switching shunt regulators (SSUs) and battery charge and discharge units (BCDUs) to a nominal voltage of $160 \mathrm{Vdc}$. The primary $\mathrm{DC}$ voltage is in turn converted by $6.25 \mathrm{~kW}$ DC/DC Converter Units (DDCUs) to $123 \mathrm{VDC}$ for use in the secondary electric power distribution system
(SEPDS). SEPDS onboard the Space Station is defined as the DDCUs, cables, protective devices, core loads, and payloads. Each secondary power system has a unique architecture in terms of the number of connected loads and payloads. The cables (types and lengths) that connect these loads to secondary distribution power buses are different for each SEPDS. The Space Station SEPDSs include many different system topologies with different number of connected loads of varying power levels. A typical SEPDS bus is shown in Figure 1. The Space Station consists of isolated power buses (primary and secondary distribution buses) to meet the required fault isolation and redundancy requirements.

Due to size and complexity of the Space Station power system the system is defined in terms of several smaller subsystems, and each subsystem is designed individually. The subsystems then are integrated to form a complete system. Subsystems that include international partners such as the European Space Agency (ESA), Japanese Space Agency (NASDA), the Russian modules and the payload subsystems are designed independent of each other. Even though the subsystems are designed properly, stability can be a problem after system integration. There is always the potential that different subsystems may interact with each other because of negative resistance characteristics of the switching DC/DC converters. This may result in poor power quality and in extreme cases system instability. Therefore, it is extremely important to develop proper requirements for various subsystems and to further test or analyze these systems under various configurations and operating conditions. The requirements for these interfaces at various subsystems were developed in advance to ensure system stability after integration of these subsystems. A detail description of the small signal stability requirements is given in Gholdston et. al., 1996.

In order to verify that the system meets its various performance requirements, many system operating conditions must be analyzed or tested. Also, these performance measures need to be verified under many system uncertainties such as component aging and load variations. Testing large scale systems consisting of hundreds of DC/DC converters becomes extremely expensive. It is necessary that the tests be performed on a limited number of scenarios where 
potential for subsystem interaction and instability exists. We use the model of the power system to perform analysis on the compatibility of various DC/DC converters. The model is also used to determine the "worst cases" which are then candidates for extensive laboratory testing. This results in tremendous cost savings as compared with testing all the multiple scenarios.

The secondary power distribution systems are more complex due to the fact that many different types of load converters of different power levels are used. The sources in the secondary power system were given a maximum output impedance requirement. Based on these maximum source impedances, the source impedances at the input of various loads and at Space Station interfaces were derived. Computer simulation based on Boeing's EASY5 software was used to model these SEPDS and derive these impedances. Load input impedance and interface impedance requirements were then specified at these interfaces based on the concept of gain limits and allowable phase regions [Gholdston et. al., 1996]. For the secondary power system loads, a $3 \mathrm{db}$ limit was added to $\left|Z_{S}\right|$ at various locations. The load input impedance then was required to stay above this limit. For frequencies where $\left|Z_{S}\right|>\left|Z_{L}\right|$, the phase of $Z_{L}$ was required to stay outside of an allowable region such that $Z_{S} / Z_{L}$ maintains a 30 degree phase margin.

The impedance requirements ensure small signal stability of the integrated system. In order to ensure large signal stability of the system, large signal stability test requirements for loads and sources were developed. These included various large signal tests for sources that included line and load changes under various bus voltages and loading scenarios. The loads were also required to maintain stability under line and load step changes.

We have used the statistical method of Design of Experiments as a tool to analyze the behavior of the SEPDSs as a function of system uncertainties. DoE also identifies which system operating conditions are the most critical. The most critical conditions are then tested to verify system design limits.

In this paper a brief description of the modeling approach that was used to assess the small signal stability of the ISS SEPDS is given. We describe a modular modeling approach and methods to analyze interaction among DC/DC converters. Next, we describe the statistical method of Design of Experiments. Applications of DoE to verification of SEPDS is presented. Some examples where we have used DoE to identify worst case system conditions (lowest stability margin) are presented.

\section{VERIFICATION OF EPS STABILITY}

The stability of the ISS EPS will be verified/demonstrated by a combination of analysis and directed test. In an ideal case, stability would be demonstrated via testing only. Unfortunately, due to extreme cost and schedule constraints on the ISS program, the program has been forced to rely heavily on performing analytical calculations supported by specific directed tests.

For many system configurations, electrical power system stability will primarily be demonstrated/verified utilizing analysis. This analysis will employ simulation tools to predict the system behavior. These simulations will be composed of electrical component (i.e. power supplies, cables, connectors, etc.) models that are connected to match the system topology by stage and operational configurations. Whenever possible, these models will be compared to test data and modified accordingly as a model validation process. The validity of any given model, however, needs to be understood and documented. As an example, a linearized power converter model would be valid for a power range that did not result in discontinuous switching and a current range that did not invoke its current limiting functions.

To verify complete system stability, both small signal and large signal stability must be demonstrated. In order to demonstrate small signal stability, analysis will be performed over a frequency range to assess system stability about a given steady state operating point. Linearized component models will be used for this analysis. Primarily, this analysis will rely on gain an $\rfloor$ phase margin comparisons as an indication of system stability. In order to demonstrate large signal stability, an examination of the system response to a sudden and severe disturbance (such as load starting or fault clearing) will be made. Nonlinearities in the system must be accounted for in the analytical model to perform this type of analysis. The transient analysis results will then be compared to system performance requirements as an indication of system stability. Once both linear and nonlinear stability has been demonstrated, the system shall be considered stable.

In order to validate the accuracy of the models used for both small and large signal stability analysis, the ISS program plans to perform both box/component level and system level tests. Data gathered as part of this test process will then be used to validate both box level and system level models. These tests will be composed of both frequency domain and transient testing. This will enable data to be produced to validate both the large and the small signal analysis process and therefore enable the demonstration of system stability through analysis.

\section{MODELING APPROACH}

A modular approach is used in modeling and analysis of distributed power systems. The components and subsystems of the system are modularized and subsequently interconnected to form the complete system. Modularizing the system into components and subsystems has several advantages: 1) it reduces the complexity of analyzing large systems by analyzing a less complex subsystem, 2) subsystems and component models can be verified with manageable test conditions, 3) component and subsystem models can be used in different systems.

Large DC power systems such as the Space Station power system use multiple levels of $\mathrm{DC} / \mathrm{DC}$ conversions via switching regulators with different characteristics. The complexity of these systems requires that the computer models be fast and not require a significant amount of a computer memory. These models must be flexible such that future modifications are possible when the design matures, or test data becomes available and can be used for validation. 
The Space Station secondary power systems was modeled using EASY5x (Karimi, 1993). Since the system model is developed as an interconnection of several smaller models, a mathematical description of each component model was developed. The mathematical model is written in terms of port voltages and currents to make it suitable for two port modeling.

Modeling of DC/DC converters is the critical part of developing a reliable system model. It is extremely important that models be developed for the power converters such that subsystems and system level analysis can be performed. The converters can be modelled at different levels of detail. Detailed models which include all the circuit elements are not practical for large systems due to heavy simulation time involved with these models. Converters are broken up into subsystems and each subsystem is modeled behaviorally (control loops) or in detail.

We have developed a library of various switchmode $D C / D C$ converter topologies in EASY5x which are based on averaging techniques. These models were developed to perform small signal analysis and were developed for voltage mode and current mode regulators. The models used for system level analysis use averaging techniques to avoid heavy simulation times associated with detailed PWM circuit level DC/DC converter models. The models were also developed for maximum flexibility. Many of the converter models share the same macros for input filter, power stage, and control loops (Karimi, 1993).

Various Space Station secondary power systems such as the U.S. Laboratory (U.S. LAB) secondary power systems has been modeled using EASY5x.These models include models of sources (6.25 kW DC/DC converter), cables, Remote Power Controller Modules
(RPCMs), and various loads such as heaters, lights, and multiple $\mathrm{DC} / \mathrm{DC}$ converters.

\section{SYSTEM PERFROMANCE ANALYSIS}

When integrating various $\mathrm{DC} / \mathrm{DC}$ converters with constant power characteristics or subsystems containing multiple DC/DC converters, the potential for subsystem interaction exists (Gholdston et. al., 1996). In many cases the system can experience oscillatory behavior or in extreme cases, instability. R.D. Middlebrook (1976) considered the interaction of a DC/DC converter and its input EMI filter. A source impedance $Z_{S}$ was defined as the output impedance of the input EMI filter. Load impedance $Z_{L}$ was defined as the input impedance of the switching regulator. Conditions for stability and performance of the interconnected system were derived. The same concept has been applied to the integration of various subsystems of the ISS power system. Various parts of .he DC power system are broken into source and load subsystems and source impedance $Z_{S}$ and load impedance $Z_{L}$ are defined for each interface. A converter feeding multiple paralleled converters is considered the source subsystem with its output impedance defined as the source impedance. The aggregate input impedance of multiple parallel converters is defined as the load subsystem. In our system model, load and source impedances at various interfaces are calculated and validated with test data when available.

\section{DESCRIPTION OF THE EXPERIMENTS}

We describe experiments to assess the stability of five different Space Station power system EASY 5x models. The models represent different secondary power system buses. The goal of each experiment was to predict the worst case stability margin

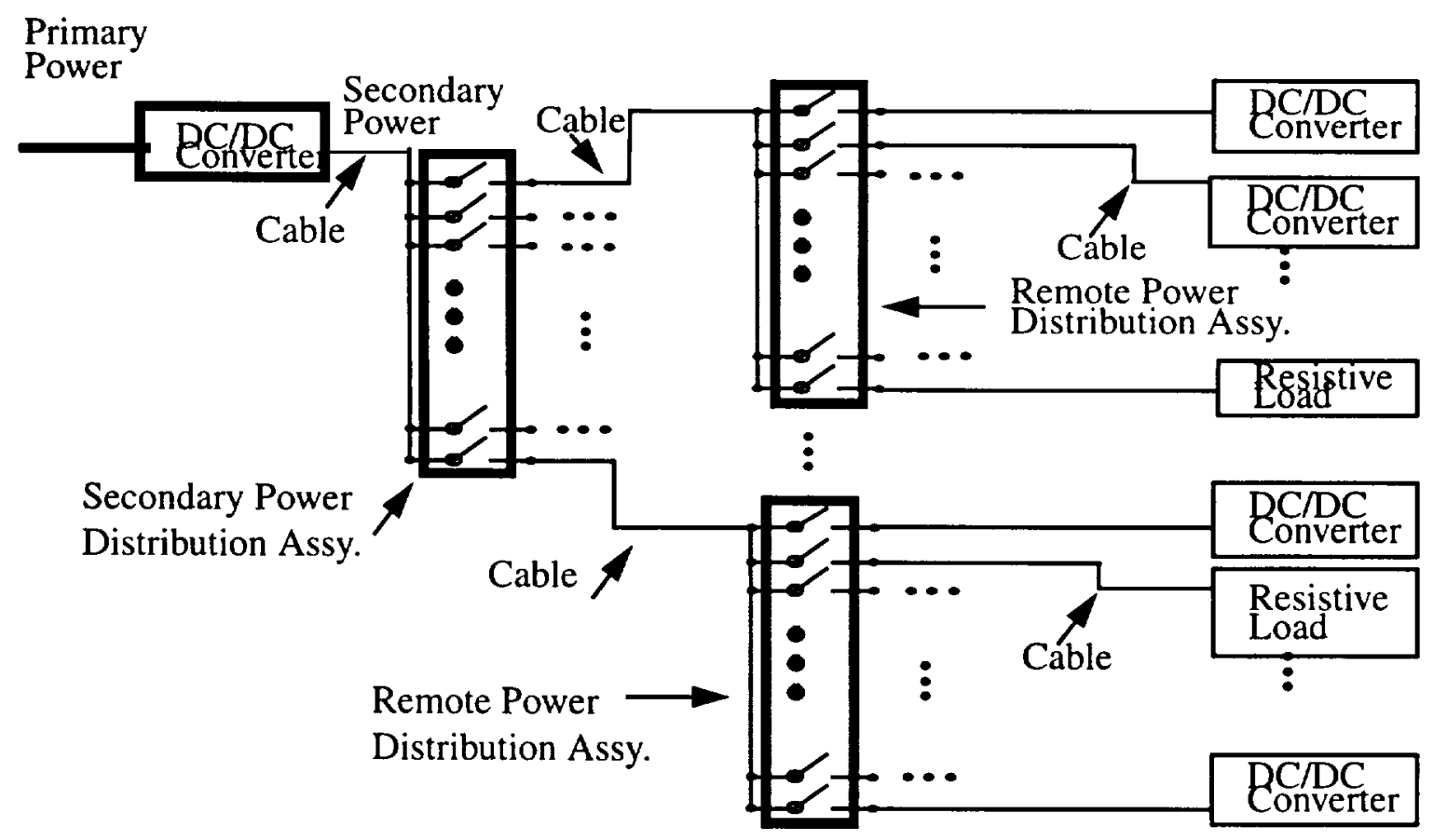

Figure 1- Typical Secondary Electric Power Distribution System 
(phase and gain margin) of the system at a particular constant power load's interface by finding combinations of ON/OFF settings of the remaining power loads that yield minimum phase margin.

The phase margins of $Z_{S} / Z_{L}$ at various interfaces of the system were calculated using the EASY5x models. The source impedances $\left(Z_{S}\right)$ at any interface is a function of the upstream cables, the state of the DC/DC power converter units in the system, and the ON/OFF state of all remote power controller switches. Any remaining remote power controller switch that is ON changes the source impedance of the load that is being controlled.

There were three models of the U.S. LAB secondary power system and two models of NODE-1 that were used in this study. We list them along with the number of interfaces to be examined:

\author{
U.S. LAB Forward \\ U.S. LAB Aft \\ U.S. LAB Rack LAP6 \\ NODE-1 Channel 3B (F3A) \\ NODE-1 Channel 3B (F2A)
}

A single experiment consisted of a series of EASY 5x runs to determine the combination of ON/OFF status of switches (loads connected to the secondary bus) yielding worst case phase margin at a single interface. A system model may have as many as 30 loads. To examine at each interface all combinations of ON/OFF of the remaining loads could require, as in the case of the U.S. LAB Aft model, as many as $30 * 2^{29}$ EASY $5 x$ runs. Thus a more efficient method was sought.

\section{DESIGN OF EXPERIMENTS}

Design of Experiments is a statistical discipline for systematically and efficiently designing and analyzing experiments to answer specific questions. The large body of case studies and industrial experiments documented is a subject for another paper. A good overview of $\mathrm{DoE}$ and its role in engineering problems is given in Box and Bisgaard (Box et al, 1987).

In the context of this Space Station Power system analysis DoE provides experiments for estimating and analyzing "effects" of turning power loads ON and OFF. Effects are additive (not linear) contributions to phase margin of turning power loads or combinations of power loads ON and OFF. Knowledge of all effects characterizes the system in terms of all combinations of power load ON/OFF states.

Our experiments were designed for analyzing main effects (the effect a power load has on the phase margin independent of the other power loads) and most of the time for two-way interaction effects (the joint effect of two power loads on the phase margin). When a two-way interaction effect is present, the change in phase margin due to change in one power load depends on the setting of some other power load. In an analogous way one may speak of three-way and higher order interaction effects. See Box, Hunter

and Hunter, 1978 for more detail.

DoE theory for experiments with variables that take on only 2 values ("2-level fractional factorial experiments"), for example, ON/OFF states for power loads, is particularly applicable to these experiments. This theory is well understood and discussed in detail in Box, Hunter and Hunter, 1978. As mentioned above the "full factorial" experiment, all combinations of ON/OFF loads, may require a prohibitive number (as many as $30 * 229$ ) of EASY $5 \mathrm{x}$ runs. Thus a "fractional factorial" experiment is called for in which a judiciously chosen subset of the full factorial combinations of ON/OFF states for each power load is run. Choosing this subset, termed "fractionating" implies sacrificing the ability to get some information out of the experiment, in particular, the ability to estimate high order effects.

\section{RUNNING EXPERIMENTS}

A single experiment may call for as many as 1024 EASY 5x runs. This is a prohibitive number of experiments to do manually. Thus the experiments were automated. The SAS software package was used to generate the ON/OFF combinations of the loads to run in the experiment. A C program used the SAS generated file and files describing the EASY5x models to automatically run EASY $5 x$ in batch mode and to run a Fortran program on EASY 5x plot output files for each experimental run determining the frequency at which the $Z_{S} / Z_{L}$ crossover occurred, and the phase margin at that crossover. Although the total machine time required to perform these series of analyses ran into the hours, only about one man-hour was required for analysis setup of the 30 analysis series.

\section{DoE ANALYSIS}

DoE analysis produces quantitative and qualitative information about the effects being estimated in the experiment. For detailed discussions of the analysis methods used in the examples in this paper see Box, Hunter and Hunter, 1978.

It is important to mention that many of the runs resulted in separation of load and source impedance magnitudes and yielded no phase margin in the chosen frequency range; i.e., the Nyquist plot did not cross the unit circle. In these cases we considered the phase margin to be large (infinite) and set the response to the maximum value observed in the experiment.

The importance of effects is measured by computing the main effects' and interactions' percent contributions to the "energy" (sum of squares) in the phase margin. We refer to this process as Analysis of Variance (ANOVA). The ANOVA can be represented graphically in a pie chart as in the example in Figure 3. The chart shows that the main effect due to load L9 is the most important effect with a $60.9 \%$ contribution, with a $32.1 \%$ contribution from the main effect due to load $\mathrm{L} 15$ and a small $3.7 \%$ contribution from the main effect due to load L22. The main effects are also graphically depicted as in the example in Figure 2 . The centerline in the figure is the mean value of the observed phase margins. The lines show the change from mean value in phase margin when a 
load is ON or OFF (or it's effect!) Thus the plot shows that the mean phase margin observed in the experiment was about 30.8 degrees and setting Load L9 to OFF would reduce the phase margin about 1.7 degrees to 29.1 degrees. The worst case predicted is with loads L9, L15, and L22 all in OFF mode with negligible effects from the rest of the loads.

Example 2 (Figures 4 and 5) shows variations of phase margin of $\mathrm{Z}_{\mathrm{S}} / \mathrm{Z}_{\mathrm{L}}$ at a different interface. Here we see that switching load $\mathrm{X} 9$ from $\mathrm{OFF}$ to $\mathrm{ON}$ reduces the phase margin by 10 degrees.

The analysis and graphical display were deemed easy to understand by the engineer and it was noted that the DoE analysis (ANOVA and main effects) would have been very informative even if one had not used a DoE methods to reduce the number of runs and had done all ( $2^{29}$ in the example) possible runs.

Some questions remain as to how to rigorously determine important variables. Our experience was that effects whose sums of squares were less than the residual sum of squares should be examined further. The residual sum of squares is the sum of squared errors from the least squares model fits implicit in the ANOVA and main effect analysis. See Box, Hunter and Hunter, 1978. In particular, if all the estimated effects' sums of squares were less than the residual sum of squares then the design resolution was inadequate and a higher resolution design had to be run. We cannot conclude, however, that the converse is true, i.e., if all the estimated effects' sums of squares were greater than the residual sum of squares then the design resolution was adequate. Thus this approach is an heuristic approach and not a rigorous determination of the lack of importance higher order effects.

\section{CONFIRMATION}

We recommend some set of runs to confirm the results of the analysis. To confirm the importance of the effects and variables deemed important in the first experiment, fix the state of unimportant variables and perform another higher resolution (able to estimate higher order interactions) designed experiment in the remaining important variables. Thus in the example one may run all 8 combinations of ON/OFF in the variables L9, L15 and L22 (with the other variables fixed) to confirm that "all OFF" is the worst case and that the two-way and three-way interactions are in fact not important. To confirm the relative unimportance of variables use EASY5x runs with important variables at "worst case" values and the other variables varying randomly or in a systematic low resolution design. If the resulting phase margin values are all close to the predicted "worst value" then one has (heuristically) confirmed that the "unimportant" variables have very small effect on the phase margin.

\section{SUMMARY}

Design of Experiments has been applied to verification of the ISS secondary power system. DoE reduces the required number of computer runs for system performance analysis. DoE helps to identify worst case system operating conditions for a large complex power system. The identified cases are then candidates for extensive testing to verify the stability of the system.

\section{REFERENCES}

E. W. Gholdston, K.J.Karimi, F.C.Lee, J.Rajagapalan, Y.Panov, B.Manners, 1996, "Stability of Large DC Power Systems Using Switching Converters, with Application to the International Space Station, Presented at 1996 IECEC, Washington DC pp. 166-171.

K.J.Karimi, A. Booker, A. Mong, 1996, "Modeling, Simulation, and Verification of Large DC Power Electronics Systems", 1996 Power Electronics Specialist Conference.

J.R. Lee,H.H. Cho, S.J.Kim, F.C.Lee, 1988, "Modeling and Simulation of Spacecraft Power Systems", IEEE Transactions on Aerospace and Electronics Systems Vol 24, No. 3 MAy 1988 pp 295-303 K.J. Karimi, 1993, "Modeling and Simulation of Distributed Power Systems with EASY $5 x$ ", Proceedings of International Simulation Conference, San Francisco, CA, pp. 64-69.

R. Lewis,S. Shultz, J.Liu, B.H.Cho,F.C.Lee. 1991. "Distributed Power System Analysis", Final Report to IBM Corporation,Manasas, VA, VPEC Publications.

A. Patil, P. Huynh,D.Hulielheh,C.Wildrick, A.Radhakrishnan, B.Choi, D.Sable, F.C.Lee, B.Cho, and K.Taml. 1992. "Assessment of Space Station Power System Performance and Stability" Final Report for NASA LeRC, VPI publications (Jan.).

S. Schulz, B.H.Cho, F.C.Lee. 1990. "Design Considerations For A. Distributed Power System", Power Electronics Specialist Conference, pp. 611-17.

EASY5x Users Manual, Boeing Computer Services, Seattle, WA 1993.

R.D.Middlebrook. 1976. "Input Filter Considerations in Design and Applications of Switching Regulators," IEEE Industry Applications Society Annual Meeting Record, pp. 366-382.

R.D.Middlebrook, S. Cuk. 1976. "A general unified approach to modeling switching converter power stages," IEEE Power Electronics Specialist Conference Proceedings.

V. Voperian, 1990. "Simplified Analysis of PWM converers Using Model of PWM Switch Parts I \&II,"IEEE Transactions on Aerospace and Electronics, May, 490-505.

Box, G.E.P., Hunter, W.G. and Hunter, J.S. (1978). Statistics for Experimenters. John Wiley and Sons, New York, N.Y.

Box, G.E.P. and Draper, N.R. (1987). Empirical Model Building and Response Surfaces. John Wiley and Sons, New York, N.Y.

Owen, A.B., (1992). Orthogonal Arrays for Computer Experiments, Integration and Visualization. Statistical Sinica,

Sacks, J., Welch W.J., Mitchell, T.J. and Wynn, H.P. (1989)

Design and analysis of computer experiments (with comments) Statistical Science, 4, 409-435.

Taguchi, Genichi and Yuin Wu, Introduction to Off-line Quality' Control. (Nagoya, Japan: Central Japan Quality Control Association, 1980)

Box, G. E. P. and Soren Bisgaard, "The Scientific Context of Quality Improvement”, Qualing Progress. June, 1987. 


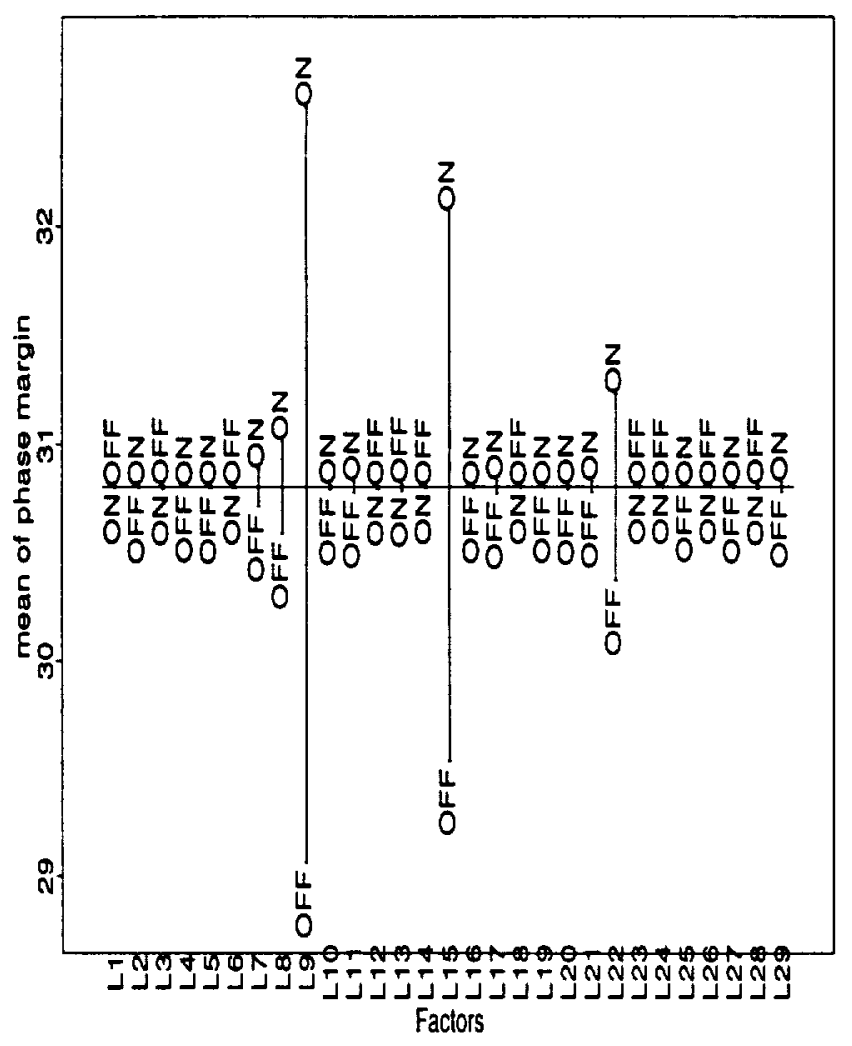

FIGURE 2- ON/OFF EXPERIMENT RESULTS FOR EXAMPLE 1

\section{Effect Importance}

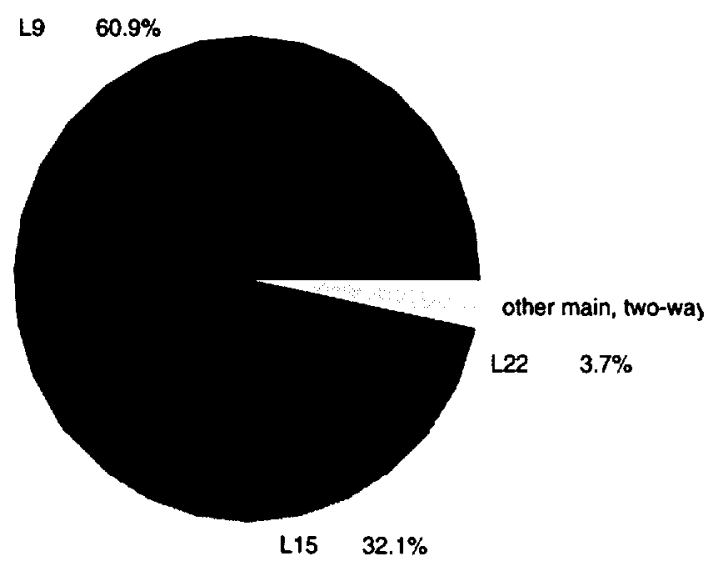

FIGURE 3- EFFECT IMPORTANCE FOR EXAMPLE 2

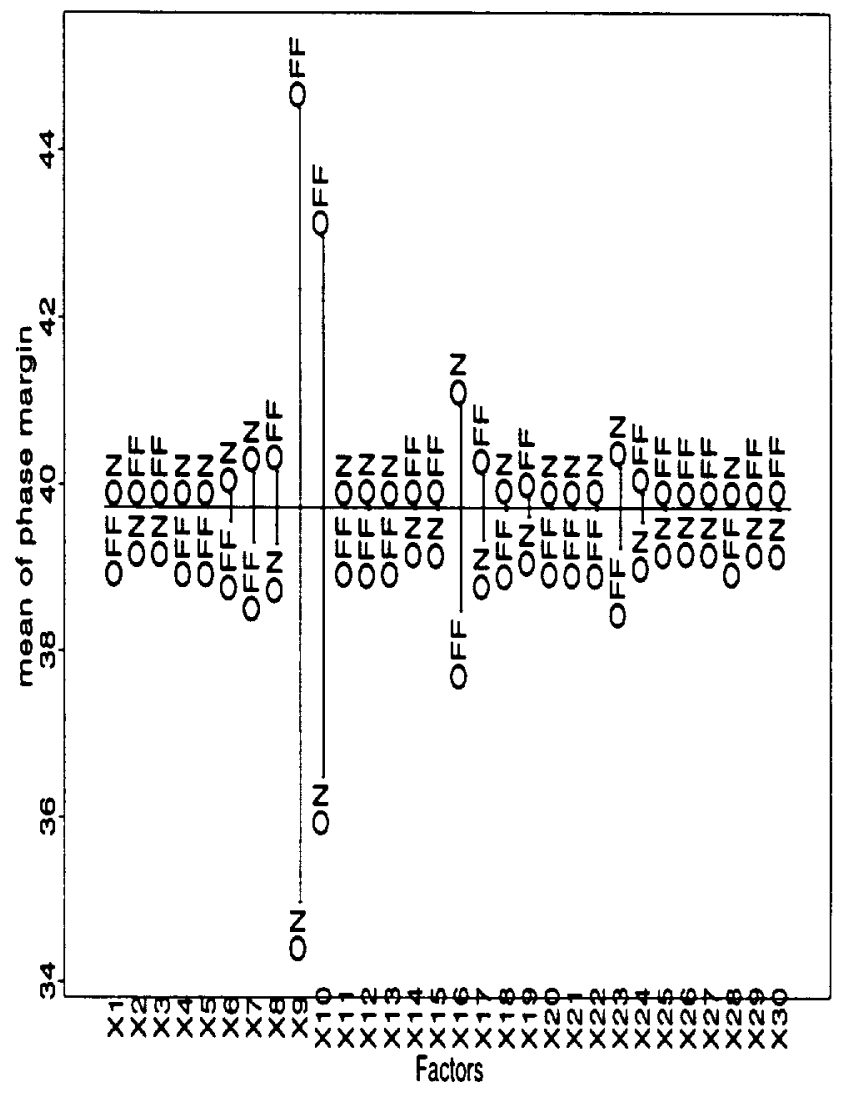

FIGURE 4- ON/OFF EXPERIMENT RESULTS FOR EXAMPLE 1

\section{Effect Importance}

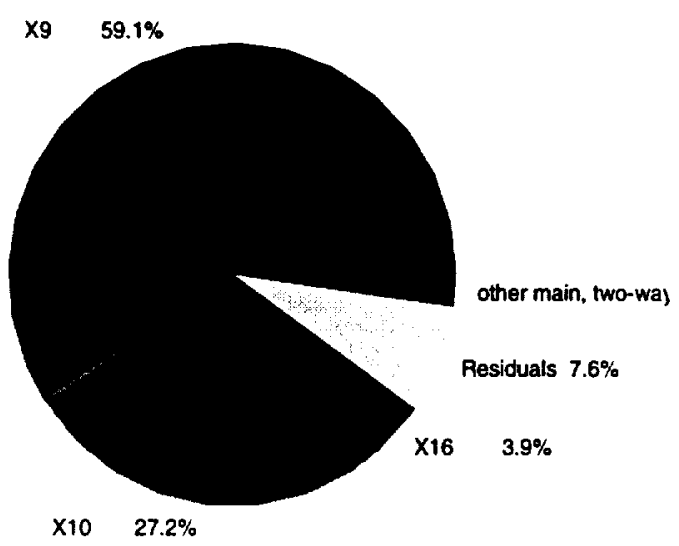

FIGURE 5- EFFECT IMPORTANCE FOR EXAMPLE 2 

Public reporting burden for this collection of information is estimaled to average 1 hour per response, including the time for reviewing instructions, searching existing data sources, gathering and maintaining the data needed, and completing and revlewing the collection of information. Send comments regarding this burden estimale or any other aspect of this collection of informatlon, heluding suggestions for reducing this burden, to Washington Headquarters Services, Directorate lor Intormation Operations and Reports. 1215 Jefferson Davis Highway, Sulte 1204, Artington, VA 22202-4302, and to the Otfice of Management and Budget, Paperwork Reduction Project (0704-0188). Washington, DC 20503.

\begin{tabular}{|l|l|l|} 
1. AGENCY USE ONLY (Leave blank) & 2. REPOAT DATE & 3. REPOAT TYPE AND DATES COVERED
\end{tabular}

4. TITLE AND SUBTITLE

January 1998

Technical Memorandum

Verification of Space Station Secondary Power System Stability

Using Design of Experiment

6. AUTHOR(S)

Kamiar J. Karimi, Andrew J. Booker, Alvin C. Mong, and Bruce Manners

\section{PERFORMING ORGANIZATION MAME(S) AND ADDRESS(ES)}

National Aeronautics and Space Administration

Lewis Research Center

Cleveland, Ohio 44135-3191

9. SPONSORING/MONITORING AGENCY NAME(S) AND ADDRESS(ES)

National Aeronautics and Space Administration

Washington, DC 20546-0001
WU-478-29-10-00

5. FUNDING NUMBERS

8. PeRforming organization REPORT NUMBER

E-11020

10. SPONSORING/MONITOAING AGENCY REPORT NUMBER

NASA TM-1998-206531

\section{SUPPLEMENTARY NOTES}

Prepared for the 32nd Intersociety Energy Conversion Engineering Conference cosponsored by AIChE, ANS, SAE, AIAA, ASME, and IEEE, Honolulu, Hawaii, July 27-August 1, 1997. Kamiar J. Karimi, Andrew J. Booker, and Alvin C. Mong, Boeing Information and Support Services, MS 7L-25, Seattle, Washington 98124; Bruce Manners, NASA Lewis Research Center. Responsible person, Bruce Manners, organization code 6920, (216) 433-8341.

12.. DISTRIBUTIONAVAILABILITY STATEMENT

12b. DISTRIBUTION CODE

Unclassified - Unlimited

Subject Categories: 18, 20, and 33

Distribution: Nonstandard

This publication is available from the NASA Center for AeroSpace Information, (301) 621-0390.

\section{ABSTRACT (Maxlmum 200 words)}

This paper describes analytical methods used in verification of large DC power systems with applications to the International Space Station (ISS). Large DC power systems contain many switching power converters with negative resistor characteristics. The ISS power system presents numerous challenges with respect to system stability such as complex sources and undefined loads. The Space Station program has developed impedance specifications for sources and loads. The overall approach to system stability consists of specific hardware requirements coupled with extensive system analysis and testing. Testing of large complex distributed power systems is not practical due to size and complexity of the system. Computer modeling has been extensively used to develop hardware specifications as well as to identify system configurations for lab testing. The statistical method of Design of Experiments (DoE) is used as an analysis tool for verification of these large systems. DoE reduces the number of computer runs which are necessary to analyze the performance of a complex power system consisting of hundreds of DC/DC converters. DoE also provides valuable information about the effect of changes in system parameters on the performance of the system. DoE provides information about various operating scenarios and identification of the ones with potential for instability. In this paper we will describe how we have used computer modeling to analyze a large DC power system. A brief description of DoE is given. Examples using applications of DoE to analysis and verification of the ISS power system are provided.

\begin{tabular}{|c|c|c|}
\hline \multicolumn{3}{|l|}{$\begin{array}{l}\text { 14. SUBJECT TERMS } \\
\text { Stability; Analysis; Design o }\end{array}$} \\
\hline $\begin{array}{l}\text { 17. SECURITY CLASSIFICATION } \\
\text { OF REPORT } \\
\text { Unclassified }\end{array}$ & $\begin{array}{l}\text { 18. SECURITY CLASSIFICATION } \\
\text { OF THIS PAGE } \\
\text { Unclassified }\end{array}$ & $\begin{array}{l}\text { 19. SECURITY CLASSIFICATION } \\
\text { OF ABSTRACT } \\
\text { Unclassified }\end{array}$ \\
\hline
\end{tabular}

NSN 7540-01-280-5500

\begin{tabular}{l} 
15. NUMBER OF PAGES \\
12 \\
$\begin{array}{c}\text { 16. PRICE CODE } \\
\text { AO3 }\end{array}$ \\
\hline
\end{tabular}

